\title{
Tailoring of Two-dimensional Electron Gas Density in Thin Film Oxide Heterostructure via Atomic Layer Deposition
}

\author{
Seong Hwan Kim, Hye Ju Kim, and Sang Woon Lee \\ Department of Energy Systems Research and Department of Physics, Ajou University \\ Suwon 16499, Republic of Korea \\ pucksae77@ajou.ac.kr; ajuphysics@ajou.ac.kr; slee01@ajou.ac.kr
}

\section{Extended Abstract}

Recently, oxide heterostructure-based two-dimensional electron gas (2DEG) has received intensive attentions owing to their interesting properties. The model system is epitaxial $\mathrm{LaAlO}_{3}$ (LAO) grown on single crystalline $\mathrm{SrTiO}_{3}(\mathrm{STO})$ substrate.[1] Electrons with a density of $10^{13} \sim 10^{14} / \mathrm{cm}^{2}$ were observed which moves freely along in-plane direction while they are confined within $\sim 2 \mathrm{~nm}$ (out-of-plane direction). Unfortunately, the adjustment of electron density was not available for the epitaxial LAO/STO heterostructure. In addition, the growth of epitaxial LAO film requires a high-temperature process $\left(700 \sim 800^{\circ} \mathrm{C}\right.$ ) using pulsed laser deposition technique.

Here, we demonstrated a creation and control of $2 \mathrm{DEG}$ at the interface of non-epitaxial $\mathrm{Al}_{2} \mathrm{O}_{3} / \mathrm{TiO}_{2}$ thin film heterostructure using atomic layer deposition (ALD). The electron density can be tailored from $\sim 10^{11} / \mathrm{cm}^{2}$ to $\sim 10^{14} / \mathrm{cm}^{2} \mathrm{by}$ the control of ALD process temperature because the electrons are coming from oxygen vacancies at the interface of $\mathrm{Al}_{2} \mathrm{O}_{3} / \mathrm{TiO}_{2}$ heterostructure of which oxygen vacancy density is governed by kinetics during the ALD process. Electron density up to $\sim 10^{14} / \mathrm{cm}^{2}$ was achieved at the interface of the $\mathrm{Al}_{2} \mathrm{O}_{3} / \mathrm{TiO}_{2}$ heterostructure which is 100 times higher than that of the conventional semiconductor heterojunction such as $\mathrm{AlGaAs} / \mathrm{GaAs}$.

The 2DEG at $\mathrm{Al}_{2} \mathrm{O}_{3} / \mathrm{TiO}_{2}$ heterostructure can be applied for the development hydrogen $\left(\mathrm{H}_{2}\right)$ gas sensor. A highperformance, transparent, and extremely thin $(<15 \mathrm{~nm})$ hydrogen gas sensor was fabricated using 2DEG at the interface of $\mathrm{Al}_{2} \mathrm{O}_{3} / \mathrm{TiO}_{2}$ heterostructure grown by ALD. [2] Palladium nanoparticles $(\approx 2 \mathrm{~nm}$ in thickness $)$ are used on the surface of the $\mathrm{Al}_{2} \mathrm{O}_{3} / \mathrm{TiO}_{2}$ thin film heterostructure to detect $\mathrm{H}_{2}$. Both oxides with a wide bandgap $(>3.2 \mathrm{eV})$ have transmittance of $83 \%$ in the visible spectrum, which allows for a transparent sensor. The $\mathrm{Pd} / \mathrm{Al}_{2} \mathrm{O}_{3} / \mathrm{TiO}_{2}$ gas senor detects $\mathrm{H}_{2}$ gas quickly with a short response time of $<30 \mathrm{~s}$ even at room temperature which outperforms conventional $\mathrm{H}_{2}$ gas sensors. This sensor responds to a wide range of $\mathrm{H}_{2}$ concentration, especially from $\sim 5 \mathrm{ppm}$ to $1 \%$, implying a promising candidate for a general $\mathrm{H}_{2}$ sensor. Interestingly, the $\mathrm{Pd} / \mathrm{Al}_{2} \mathrm{O}_{3} / \mathrm{TiO}_{2}$ gas senor showed an optimal electron density for $\mathrm{H}_{2}$ detection owing to the tailoring ability of $2 \mathrm{DEG}$ at the $\mathrm{Al}_{2} \mathrm{O}_{3} / \mathrm{TiO}_{2}$ heterostructure. Particularly, a sensitivity was as low as $3 \%$ for a $2 \mathrm{DEG}$ density of $5.6 \times 10^{13}$ $\mathrm{cm}^{-2}$ while the sensitivity was improved from $6 \%$ to $43 \%$ as the electron density decreased from $5.6 \times 10^{13} \mathrm{~cm}^{-2}$ to $4.1 \times$ $10^{11} \mathrm{~cm}^{-2}$. Besides the sensor application, other application of 2DEG will be introduced in the presentation.

\section{References}

[1] A. Ohtomo and H. Y. Hwang, "A high-mobility electron gas at the $\mathrm{LaAlO}_{3} / \mathrm{SrTiO}_{3}$ heterointerface," Nature, vol. 427, pp. 423-426, 2004.

[2] Sung Min Kim, Hye Ju Kim, Hae Jun Jung, Ji-Yong Park, Tae Jun Seok, Yong-Ho Choa, Tae Joo Park, Sang Woon Lee, "High-Performance, Transparent Thin Film Hydrogen Gas Sensor Using 2D Electron Gas at Interface of Oxide Thin Film Heterostructure Grown by Atomic Layer Deposition," Advanced Functional Materials, vol. 29, p. 1807760, 2019. 